TECHNICAL TRANSACTIONS 6/2017

CZASOPISMO TECHNICZNE 6/2017

CIVIL ENGINEERING

DOI: $10.4467 / 2353737$ XCT.17.088.6564

\author{
Paweł Boroń (pboron@pk.edu.pl) \\ Joanna Dulińska \\ Institute of Structural Mechanics, Faculty of Civil Engineering, Cracow University \\ of Technology
}

\title{
DYNAMIC RESPONSE OF A STEEL PIPELINE WITH BOLTED CONNECTIONS \\ TO A MINING SHOCK OBTAINED WITH THE SUBMODELING TECHNIQUE
}

\author{
ODPOWIEDŹ DYNAMICZNA GAZOCIĄGU Z DOCZOŁOWYMI \\ POŁĄCZENIAMI ŚRUBOWYMI NA WSTRZĄS GÓRNICZY \\ Z WYKORZYSTANIEM TECHNIKI SUBMODELINGU
}

\begin{abstract}
In this paper, the dynamic response of an overground steel pipeline to a real mining shock is presented. The submodeling method was used in the calculation. Firstly, time history analysis of a simplified beam model of the pipeline (a global model) was conducted. Secondly, the 3D model of a part of the structure over the support was created (a submodel). The submodeling analysis allowed obtaining stress distribution in the bolted connection of the pipeline segments.
\end{abstract}

Keywords: pipeline, dynamic response, mining shock, submodeling

\section{Streszczenie}

W artykule przedstawiona została analiza odpowiedzi dynamicznej naziemnego gazociągu na rzeczywisty wstrząs górniczy. W obliczeniach zastosowano technikę submodelingu. W pierwszym etapie przeprowadzono obliczenia uproszczonego, belkowego modelu całego gazociagu (model globalny). W drugim etapie zastosowano model 3D fragmentu konstrukcji, obejmujący odcinek gazociagu nad podporą (submodel). Analiza z zastosowaniem techniki submodelingu pozwoliła na dokładne rozeznanie pracy złącza gazociaggu oraz na określenie rozkładu naprężeń w kołnierzu i śrubach złącza.

Słowa kluczowe: gazociąg, odpowiedź dynamiczna, wstrząs górniczy, submodeling 


\section{Introduction}

The finite element method allows to solve problems connected with engineering objects of high structural, material and geometrical complexity. While linear analyses of regular shape structures do not result in complicated numerical models and they are not very timeconsuming, non-linear problems are very demanding as far as computer efforts are concerned. In case of, for example, large displacement problems or contact as well as failure mechanics, nonlinear analyses have to be carried out. These days, commercial engineering software allows for the realization of extremely complicated numerical models and performing nonlinear analysis $[4,6]$. However, time and cost of calculations of that type of structures grow rapidly with the complexity of the problem. Hence, a strong tendency towards simplifying numerical models and implementing very effective techniques and algorithms of calculations is observed. Nowadays, a submodeling method is one of these powerful techniques that shortens the time of calculations to a large degree.

In the paper, the analysis of the dynamic response of an overground steel pipeline $(105 \mathrm{~m}$ long) to a mining shock is presented. To accelerate calculations, the submodeling method was applied. The method allowed the analysis of the dynamic response of a bolted flange connection of two sections of the pipeline to a mining tremor without creating a 3D model of the whole structure. Due to the submodeling method, it was possible to model only a part of the pipeline, including the details of the connection. Not only had it significantly reduced the time and cost of the calculations, but it also allowed avoiding difficulties with densifying FE mesh of the model $[2,7]$.

Two FE models of the pipeline were created to calculate the dynamic response of the structure to the mining shock with the submodeling method. Firstly, a simplified beam onedimensional model, which covered the whole structure, was realized (a global model). Then, a 3D model including only a selected part of the structure was generated (a submodel). Both models were created with the ABAQUS software [1].

\section{Basic parameters of the pipeline and the flange connection technical details}

An overground steel gas pipeline was chosen for the dynamic response analysis. The pipeline consisted of 7 spans of $15 \mathrm{~m}$ in length. The total length of the pipeline was $105 \mathrm{~m}$. Such a structure can be considered as a representation of real long structures that can be modelled with one-dimensional beam models. The pipeline was supported on concrete pillars of $45 \mathrm{~cm}$ in height and $50 \mathrm{~cm}$ in width. The shape of pillars prevented overabundant displacements and a slip of the pipeline from supports. The main pipeline envelope consisted of a single pipe with an exterior diameter of $60 \mathrm{~cm}$ and a wall thickness of about $1.35 \mathrm{~cm}$. The steel pipe was not cover by any isolation material.

Considerable length of the analysed object produced compliance of connections between

parts of the structure. The typical connections in that kind of structures are welded or bolted connections. In the analysed object, bolted connections were used. The connections were 
located over the fourth support. That was the support in the middle part of the pipeline. The connections were placed on both sides of the pillar, at a distance of $55 \mathrm{~cm}$ from the support axis. The analysed connection is the most common joint that occurs in control valve location or switching gas station (Fig. 1).

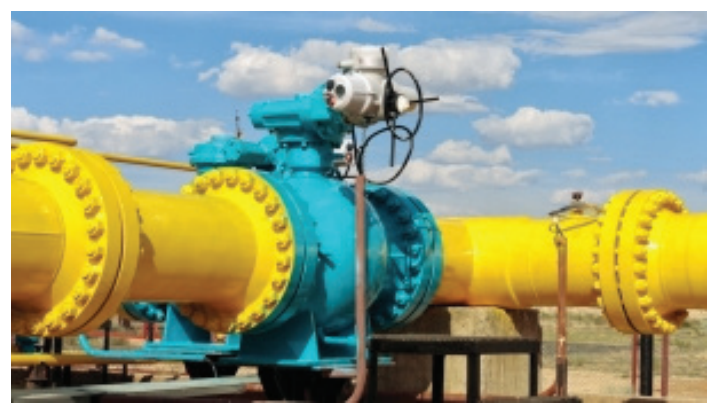

Fig. 1. Exemplary of gas network junction [5]

The connection was built as a bolted flange connection. The joint consisted of two flanges welded to the pipeline envelope. The thickness of the flange was $5 \mathrm{~cm}$. The flanges were jointed together by 24 bolts, arranged uniformly around the flange (Fig. 2). The bolts used in the connection were the M30 bolts class 5.6 (yield stress of $300 \mathrm{MPa}$, resistant stress of $500 \mathrm{MPa})$.

A

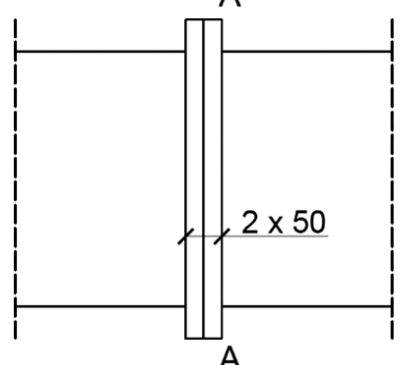

A
A-A

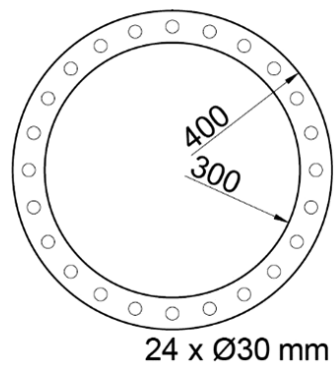

Fig. 2. Main dimensions of the pipeline segments connection

\section{General concept of the submodeling technique $[9,10]$}

For the effective analysis of the dynamic response of pipeline to a mining shock, the submodeling technique was used $[1,7-11]$. The submodeling technique is used mostly to study local parts of structures. This technique is the most useful for obtaining an accurate, detailed solution in a local region with a redefined mesh orgeometry. The submodeling analysis consists of two general steps so two numerical models (a global model and a ubmodel) were needed. 
The first step of the analysis is a global analysis. In this step, the calculation bases on models of whole structures (global models). The basic dimensions and the main characteristics of objects have to be modelled. Any simplifications in the global model, which do not change the dynamic response of a structure, were acceptable. The calculation conducted in this part of analysis allows to estimate the dynamic response of a structure. On the basis of the obtained results, it is possible to find zones of stress concentration. It also allows determining global displacements of a structure. During the global analysis, the results in the vicinity of the submodel boundaries are also received.

The second step is the analysis of a chosen part of a structure. This part is represented by a second model - called a submodel. In the submodel, as many details of the analysed part should be presented as possible. For example, details of connections as well as nonlinearity of geometry and material should be taking into account. That accuracy of the submodel increases the precision of results.

Both the global model and the submodel can have linear or nonlinear behaviour and can be analysed for any sequence of analysis procedures. For example, the linear dynamic response of the global model can be used to drive the nonlinear response of the submodel. The step time used in these analyses can also be different. The submodel and the global model can have different meshes. The size and type of finite elements in both models can differ.

The application of advanced (nonlinear) procedures and densified mesh leads to the obtainment of accurate results for submodels. It also makes it possible to present stress and strain distribution in small elements. Additionally, phenomena like local yield, stiffness degradation or contact behaviour can be determined for nonlinear submodel analysis only.

Using the proper boundary condition is the main problem of the submodeling technique. In the global model, boundary conditions arise from the real behaviour of structures. Supports and excitations are defined as displacements, velocities, accelerations or forces acting on structures. Boundary conditions in the submodel arise from the analysis of the global model.

The analysis of the submodel is carried out consecutively and separately from the analysis of the global model. The only link between the global model and the submodel is the transfer of the time-dependent values of variables obtained in the global analysis to the boundary nodes of the submodel.

During the global analysis, displacements of the whole structure are calculated and saved. Displacements of special sections (i.e. boundaries of the submodel) should especially be calculated. The values of those displacements are used as driven variables in the submodel [1]. The place of application of the boundary conditions (displacements and rotations) are the mesh nodes at the submodel ends. The other boundary conditions and loads are duplicated on the submodel from the global model. 


\section{Variants of the numerical model of the pipeline}

\subsection{Variant I - a beam model (global model)}

In order to carry out the dynamic analysis of the pipeline with submodeling technique, two variants of a numerical model were created. Variant I of the pipeline represented the structure as a multi span continuous beam (Fig. 3). In this model, real dimensions of a cross-section and length of span were taken into account. However, the true shape of support pillars were neglected - the beam was supported at eight points only. The joint supports were applied. This type of support precluded the slip of the pipe envelope from the pillars (transverse and vertical direction were fixed).

In Variant I of the numerical model, the connection of pipe segments was neither modelled nor analysed. In the dynamic analysis, kinematic excitation was applied to the supports of the pipeline. The excitation was represented by time histories of accelerations of a real mining shock.

Beam finite elements, provided by the ABAQUS software [1], were used in Variant I of the numerical model. The mesh consisted of 3500 finite elements. The length of each element was about $3 \mathrm{~cm}$. Further densification of the mesh did not introduce any noticeable changes to the results.

The beam model, which was the global simplified model of the structure, was used as the basis for further detailed analysis. The model allowed calculating stresses in the pipe envelope and also determining displacements in chosen points of the structure. The obtained displacements were used as boundary conditions in the submodel.

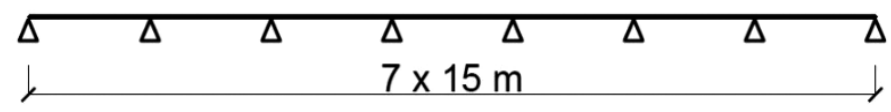

Fig. 3. Beam model of pipeline

\subsection{Variant II - 3D model of the part of pipeline (submodel)}

In the second part of analysis based on the submodeling technique, Variant II of the numerical model (submodel) was created. The main goal of the submodel analysis was an accurate calculation of the dynamic response of the flange connection. Especially, stresses in the bolts had to be determined. The submodel, created as a three-dimensional model, represented only a part of the pipeline located over the fourth support of structure. The length of the modeled part was $2.5 \mathrm{~m}$. It was situated at $43.75-46.25 \mathrm{~m}$ of the total length of the pipeline. The real dimensions of the pipeline were used in a 3D model (see Fig. 2). The flange connections were modeled in detail. They were placed symmetrically, on both sides of the supports at a $1.1 \mathrm{~m}$ offset. The geometry of the flange and the bolt-holes as well as bolts localization were precisely reflected. The $3 \mathrm{D}$ submodel of the pipeline section enabled to create the real shape of the supporting pillar. 
Variant II of the pipeline model was meshed using solid elements available in the ABAQUS software [1]. The applied finite elements were 8-node elements with 3 degrees of freedom in each node. The dimensions of elements in the pipe envelope were about $3 \mathrm{~cm}$. That size allowed comparing the results obtained for the global analysis with the results of the submodel analysis. The submodel of the pipeline is shown in Fig. 4a. The meshing of the model is shown in Fig. 4b. Additionally, special displacement boundary conditions at both ends of the submodel were added. The values of those displacements came straight from the global analysis with the beam model.

In the dynamic analysis of both Variants of the numerical model, the kinematic excitation was applied to the structure as time histories of accelerations in three directions (longitudinal, transverse and vertical).

a)

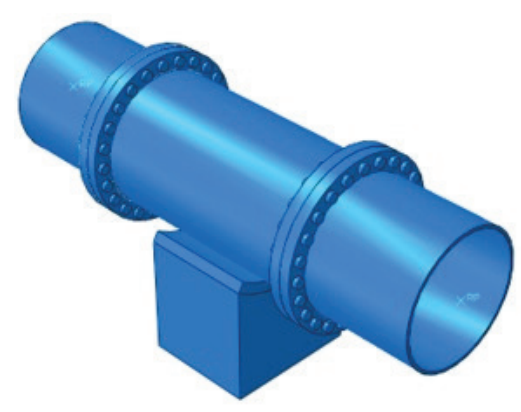

b)

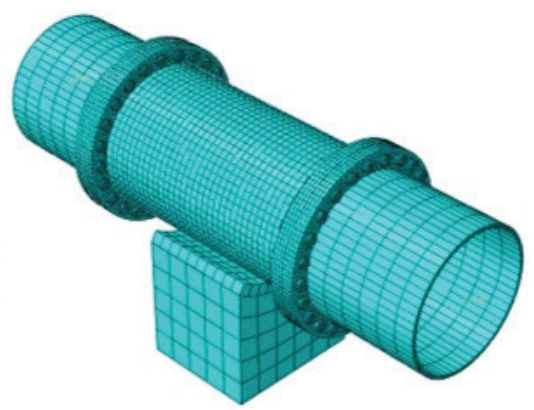

Fig. 4. 3D submodel of the pipeline (a), finite element mesh (b)

In the first step of the analysis (the global analysis with the beam model), the time histories of displacements of all nodes of the mesh were calculated and saved (three translations and three rotations). In the second step of the analysis, the displacements of chosen points, obtained during the first step, were transferred from the global beam model to the submodel. The right choice of those points in both models was an all-important issue. The points should be located at the same distance from the support in both models. In this case, the points at a distance of $1.25 \mathrm{~m}$ from the axis of fourth support were chosen where the ends of submodel were placed.

The appropriate transfer of the displacements from the beam model to the $3 \mathrm{D}$ submodel was possible due to rigid rings. The rings were hitched at the ends of the submodel. The centres of rings were located on the longitudinal axis of the pipeline. The boundary conditions (three translations and three rotations) were implemented in the centre of each ring. The use of the rigid rings allowed transferring rotations from the ring centre to the points located on the pipeline coat. Taking rotational degrees of freedom into consideration enabled to impose bending and torsional deformation of the submodel resulting from the global deformation of the whole structure, which was obtained at the first step of analysis. However, it has to be mentioned that in consequence of using rigid rings at the ends of the submodel, the circumferential deformation was neglected. 


\section{Data of the mining shock}

The dynamic analysis of the pipeline was carried out for a strong mining shock registered near Szombierki, in the Upper Silesian Coal Basin in Poland (the main region of mining activity in Poland). The time histories of ground accelerations resulting from the tremor in three directions: horizontal - parallel to wave propagation, horizontal - perpendicular to wave propagation and vertical are presented in Fig. 5.

The registered tremor, with an energy of about $1 \cdot 10^{7} \mathrm{~J}$, turned out to be one of the most severe events ever recorded in that mining area. The maximum amplitudes recorded in horizontal directions reached $0.3 \mathrm{~m} / \mathrm{s}^{2}$, whereas the amplitudes in the vertical direction were on the level of $0.12 \mathrm{~m} / \mathrm{s}^{2}$. They occurred approximately after $1.7 \mathrm{~s}$ of the shock. The Fourier analysis of the signals indicated that dominant frequencies were located within the range of $2-5 \mathrm{~Hz}$ for all directions.

a)

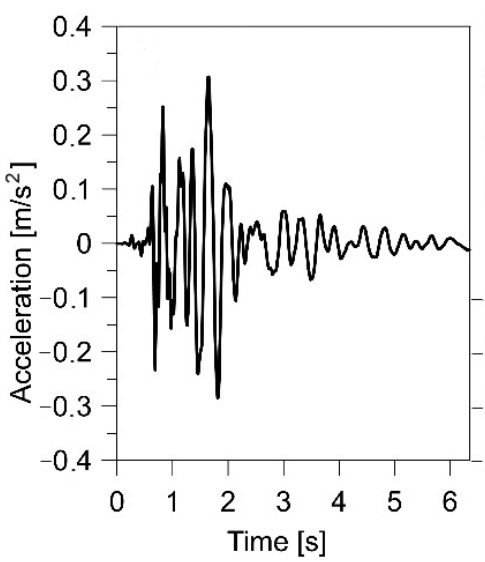

b)

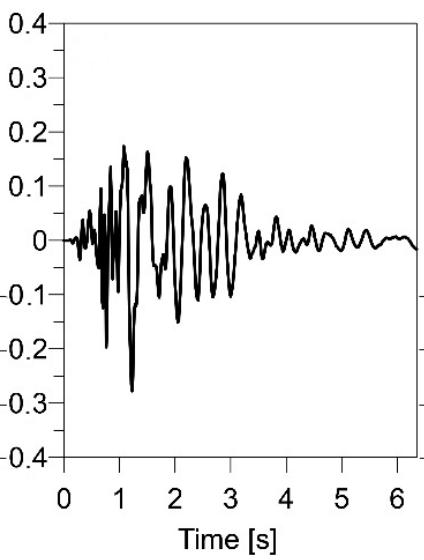

c)

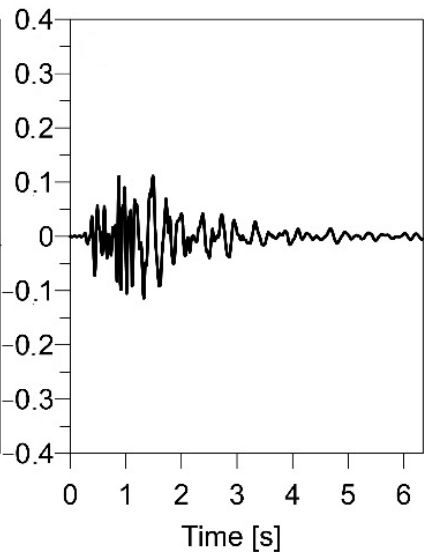

Fig. 5. Time histories of accelerations of the Szombierki mining shock in: longitudinal (a), transverse (b), vertical (c) direction

The presented time histories of accelerations were taken in the studies as the kinematic excitations of the pipeline supports. In the dynamic analysis a model of spatially varying ground motion $[3,12]$, which takes into consideration wave passage effect, was applied. In the model, it was assumed that subsequent points of the ground in the direction of wave propagation (along the pipeline) repeat the same motion with a certain time delay dependent on the wave velocity. This velocity depends on the stiffness of the bedrock; the stiffer the underlying bedrock is, the higher the velocity of wave propagation occurs. In this study, the wave velocity of $300 \mathrm{~m} / \mathrm{s}$, typical for clayey sands, was assumed. 


\section{Results of numerical analysis}

\subsection{Comparison of the dynamic response obtained for two Variants of the numerical model}

For both Variants of the numerical model (the global beam model and the 3D submodel), the dynamic response of the pipeline to the mining shock was evaluated by the time history analysis. The Hilber-Hughes-Taylor direct integration method was used for the solution of equations of motion. The Rayleigh model of mass and stiffness proportional damping was applied. The damping coefficients $\alpha=2.67$ and $\beta=0.01$ were determined for damping ratios of $5 \%$ referring to the first and the second natural frequencies: $f_{1}=7.2 \mathrm{~Hz}$ and $f_{2}=10.4 \mathrm{~Hz}$. In the dynamic calculations, the dead load was also taken into consideration.

The stress analysis for all nodes of the FE mesh of the steal pipeline coat was performed. In the paper, the results of the stress analysis were presented for two representative points only (Fig. 6).

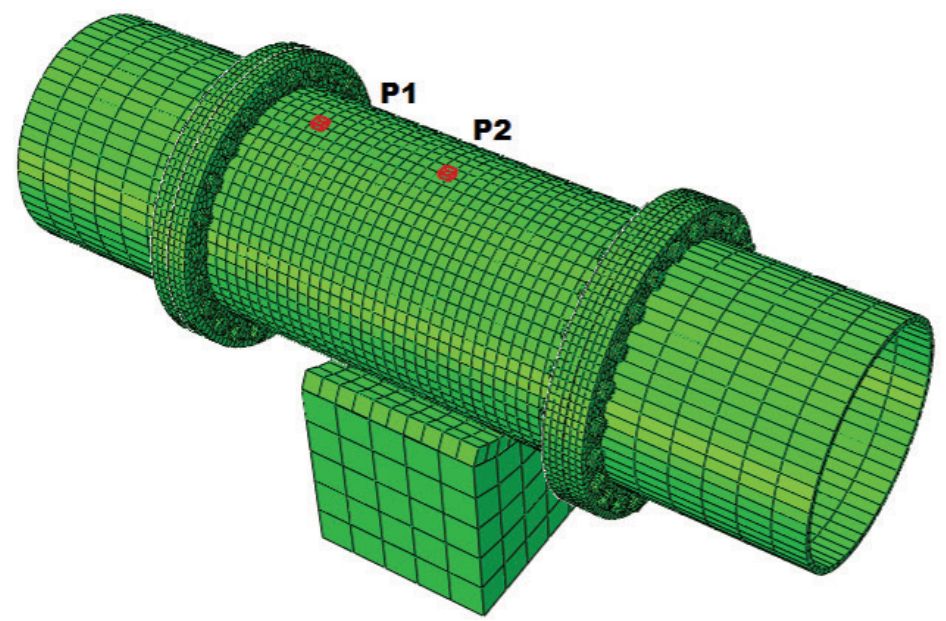

Fig. 6. Points of 3D submodel selected for the dynamic analysis

The selected points were located in the upper part of the pipe envelope. Point P1 was situated at a distance of $40 \mathrm{~cm}$ from the centre of the pipeline support, whereas point P2 is placed just above the centre of the support. The values of Mises stresses obtained at points $\mathrm{P} 1$ and P2 of the 3D submodel were compared to the values of stresses received at the corresponding points of the beam model.

The comparison of time histories of Mises stresses at point P1 that resulted from the mining shock for the beam model (dotted line) and the 3D submodel (continuous line) is presented in Fig. 7a. A similar comparison for point P2 is shown in Fig. 7b.

On the basis of Fig. 7, it can be observed that the stresses obtained for both models demonstrate the same variability in time. It is worth mentioning that the maximum values of stresses were achieved at the same moment - after $1.7 \mathrm{~s}$ of the shock - for both models. 
a)

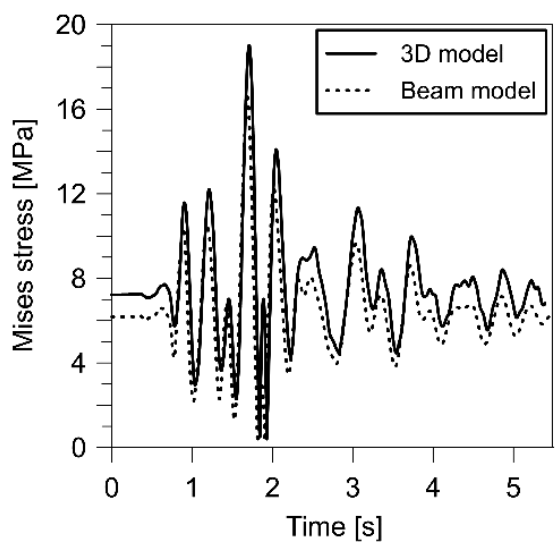

b)

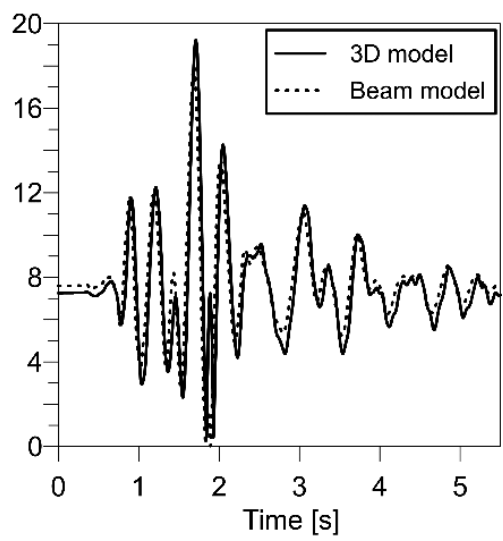

Fig. 7. Comparison of time histories of stresses for the beam model and the 3D submodel obtained at points: P1 (a), P2 (b)

The analysis of Mises stresses at point P1 (Fig. 7a) shows that the values obtained for the 3D submodel were slightly greater than those received for the beam model; however, the differences did not exceed 1.5 MPa almost the whole time. The greatest difference, which occurred for the peak values after $1.7 \mathrm{~s}$, equalled $2 \mathrm{MPa}$. The peak values obtained for the 3D submodel and the beam model were $19 \mathrm{MPa}$ and $17 \mathrm{MPa}$, respectively.

Additionally, it is clearly visible that the stresses resulting from the mining shock were significantly greater than the stresses originated from the dead load. The self-weight stresses achieved only $40 \%$ of the maximum stresses occurring due to the kinematic excitation.

It can also be observed that the dead load stresses at point P1 obtained for the beam and the 3D models slightly differed (Fig. 7a). The difference did not exceed $1 \mathrm{MPa}$. This difference occurred due to the modelling of the pipeline supports in both models. In the beam variant of the model, each support was idealized as a joint support connected with the pipeline coat at one point, whereas in the $3 \mathrm{D}$ submodel, each support was modelled with a $3 \mathrm{D}$ solid pillar of a width $0.5 \mathrm{~m}$. In consequence, a reduction of stresses at point $\mathrm{P} 1$, located $40 \mathrm{~cm}$ from the centre of the support, was much more rapid in the case of the beam model than in case of the $3 \mathrm{D}$ submodel.

The results of the dynamic analysis obtained for point P2, located at the centre of the support, also indicated similarity of time histories of Mises stresses obtained for the beam model and for the 3D submodel (Fig. 7b). The maximum difference between the values of Mises stresses for both models occurred after $1.7 \mathrm{~s}$ of the shock. It did not exceed $1 \mathrm{MPa}$ (the maximum value of the stress at this moment equalled 18.5 and $19.5 \mathrm{MPa}$ for the beam model and the $3 \mathrm{D}$ submodel, respectively). The values of stresses at point $\mathrm{P} 2$, resulting from the dead load, were identical for both models due to the fact that this point is located just above the centre of the pipeline support.

The Mises stress distribution in the 3D submodel of the pipeline coat at $1.7 \mathrm{~s}$ of the shock is demonstrated in Fig. 8. It can be seen that the maximum values of stresses appeared in the upper part of the coat and reached $20 \mathrm{MPa}$. 

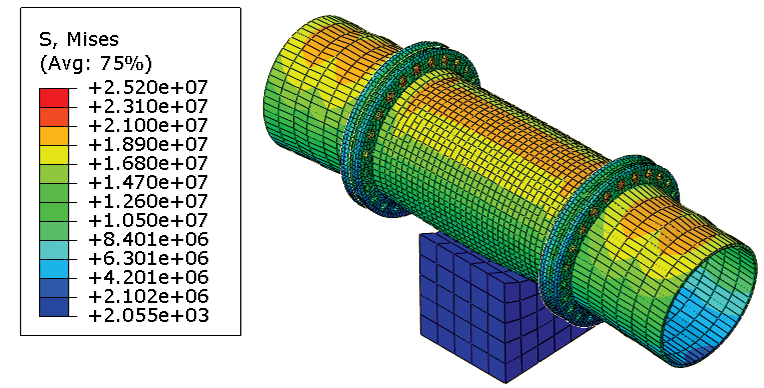

Fig. 8. Distribution of stresses in the 3D submodel (1.7 s of shock time)

\subsection{Stresses in the flange connection}

The main advantage of the submodeling technique is the possibility of precise stress calculation in selected parts of a structure. Due to this method, it was possible to observe the distribution of stresses on the contact surfaces of the flange connection.

The map of Mises stresses on the contact surface of connection, occurring at $1.7 \mathrm{~s}$ of the shock, is presented in Fig. 9. The observed stress distribution shows different values of stresses in the upper and in the lower part of the flange. It indicates that bending of the entire connection took place. The analysed map also demonstrates the concentrations of stresses around bolt-holes. The concentrations were caused by local clamping forces executed by tensioned bolts. The maximum value of stresses equalling 8.6 MPa appeared around the extreme upper bolt-hole.

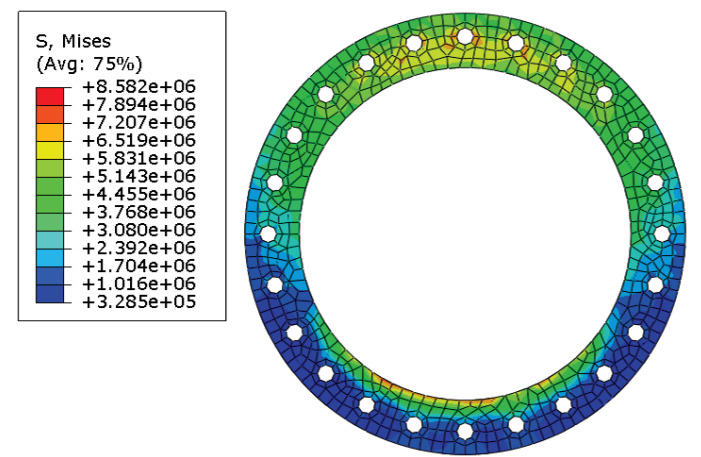

Fig. 9. Distribution of stresses on the interior flange side of the connection

In the second step of the submodel analysis, the stress distribution in the bolts was considered. The distribution of Mises stress in the bolts of the flange connection occurring at $1.7 \mathrm{~s}$ of the excitation was presented in Fig. 10. It can be seen that the maximum values of stresses appeared in the bolt shanks. The considerable difference in the stress levels can also be noticed for the bolts located in the upper and in the lower part of the connection. This indicates bending of the whole connection. 


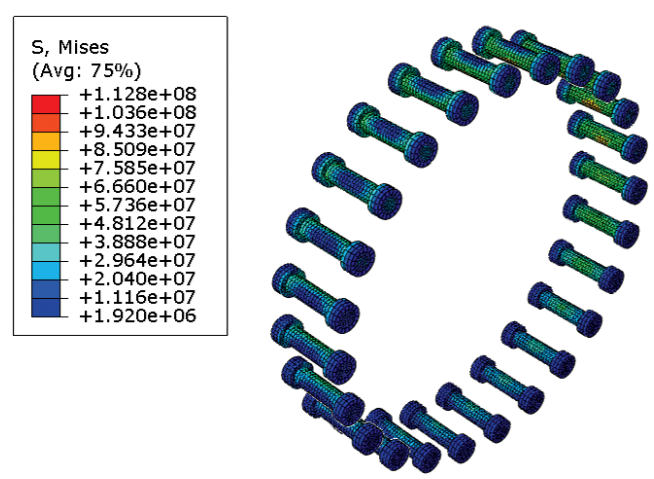

Fig. 10. Distribution of stresses in the bolts

In the next step of the analysis, the stresses in two bolt shanks were compared. The first bolt was located in the extreme upper position in the connection, whereas the second one was situated in the extreme lower part of the connection. The time histories of Mises stresses in both bolt shanks are compared in Fig. 11. The comparison shows significant differences in the dynamic response of the bolts located in the opposite parts of the connection. The stresses in the extreme upper bolt shank represented a great variability in time (Fig. 11a). During the whole shock, the values of stresses varied from 0 to $110 \mathrm{MPa}$ with the peak value at $1.7 \mathrm{~s}$ of the shock. The stresses oscillated around the value of $40 \mathrm{MPa}$, which came from the dead load of the structure. The maximum values of stresses in the extreme lower bolt shank were much smaller and the time history looked differently (Fig. 11b). The analysis of all components of stress tensor revealed that the lower bolt is tensioned once: only one peak value of $35 \mathrm{MPa}$ appeared during the whole shock, whereas the mean value resulting from the dead load was about $2 \mathrm{MPa}$.

a)

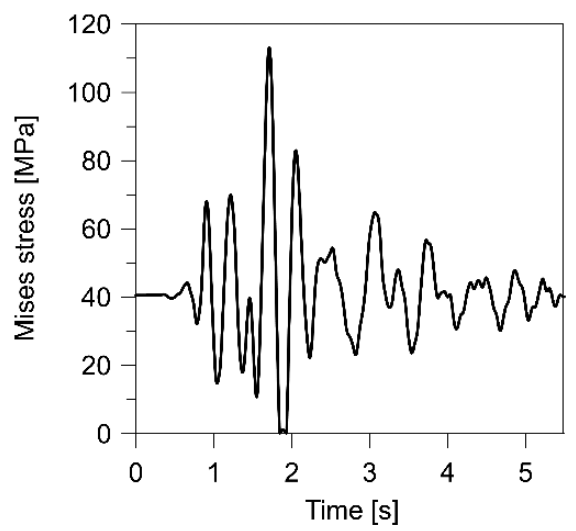

b)

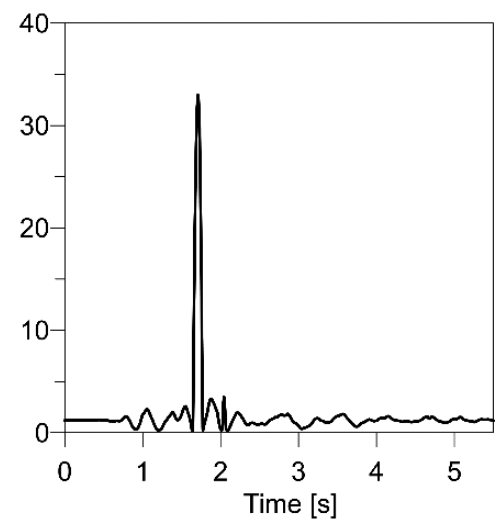

Fig. 11. Time histories of stresses in the extreme upper (a) and the extreme lower (b) bolt 
Finally, the map of Mises stresses occurring in the extreme upper bolt shank at $1.7 \mathrm{~s}$ of the shock is demonstrated in Fig. 12. The non-uniform stress distribution of the shank indicates bending of the bolt. The greatest stress of $112 \mathrm{MPa}$ appeared in the lower zone of the shank (tension), the smallest stress of $7 \mathrm{MPa}$ was found in the upper part of the shank (compression).

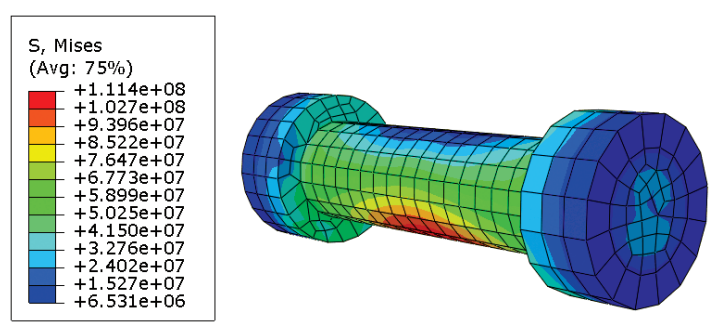

Fig. 12. Distribution of stress in upper bolt

\section{Final conclusions}

The analysis of the dynamic performance of the steel pipeline with bolted connections subjected to the mining shocks, obtained with the submodeling method, allowed the formulation of the following conclusions:

- The analysis of the dynamic response of the steel pipeline indicated that the strong mining shock caused a significant increase of stresses in the pipeline coat. The maximum values of stresses in the pipeline coat reached $20 \mathrm{MPa}$ and they were 2.5 times greater than stresses resulting from the dead load;

- At the first stage of the dynamic analysis, the simplified beam model of the pipeline was applied. At the second stage, the three-dimensional model of a part of pipeline coat with a bolted flange connection between pipeline segments was created. The submodeling technique allowed the detailed dynamic analysis of the connection work that was impossible in the case of the global beam model;

- The observation of stress distribution in the pipeline coat indicates similarity of the results received for the global beam model and the 3D submodel;

- The stress distribution on the contact surface of flanges as well as in all bolts proved that the connection was affected with strong bending;

- The analysis revealed that the dynamic stresses, which occurred in the bolt shanks due to the shock, were significantly greater than those resulting from the dead load. The maximum values of dynamic stresses reached $110 \mathrm{MPa}$ and they were almost 3 times greater than the static stresses. 


\section{References}

[1] ABAQUS 2012. User Manual V.6.12-2, Dassault Systems Simulia Corp., Providence.

[2] Abuodha S., Burdekin F., Finite element analysis of tubular joints in offshore structures, "Journal of Civil Engineering" JKUAT, Vol. 6, 2001, 105-116.

[3] Dulinska J., Jasinska D., Performance of steel pipeline with concrete coating (modeled with Concrete Damage Plasticity) under seismic wave passage, "Applied Mechanics and Materials" Vol. 459, 2014, 608-613.

[4] Garcia-Palacios J., Samartin A., Negro V., A nonlinear analysis of laying a floating pipeline on the seabed, "Engineering Structures" Vol. 31, 2009, 1120-1131.

[5] Harris P., Pipelines: The flange protection challenge. Oil \& Gas technology, 2014, http:// oilandgastechnology.net (access: 14.03.2016).

[6] Horowitz B., de Sa Barreto S., Nonlinear analysis of a prestressed steel pipeline crossing, “Engineering Structures” Vol. 28, 2006, 390-398.

[7] Lanhao Z., Tongchun L., An efficient finite element dynamic sub-modeling approach using the local mesh refinement technique, "Earth \& Space" 2008, 1-6.

[8] Li AQ Wang H., Stress analysis on steel box girders of super-longspan suspension bridges with submodel method (in Chinese), "Eng Mech" 24(2), 2007, 80-84.

[9] Wang, H., Li, A., Guo, T. et al., Accurate stress analysis on rigid central buckle of long-span suspension bridges based on submodel method, "Sci. China Ser. E-Technol. Sci." Vol. 52, 2009, 1019-1026.

[10] Wang H., Li A., Hu R., Li J., Accurate Stress Analysis on Steel Box Girder of Long Span Suspension Bridges Based on Multi-Scale Submodeling Method, "Advances in Structural Engineering" Vol. 13, No. 4, 2010, 727-740.

[11] Xu W, Li Z, Zhang XN., Application of submodeling method for analysis of deck structure of diagonal cable-stayed bridge with long span (in Chinese), "China Civil Engineering Journal" 37(6), 2014, 30-34.

[12] Yong Y., Response of pipeline structure subjected to ground motion excitation, "Engineering Structure" Vol. 19, 1997, 679-684. 